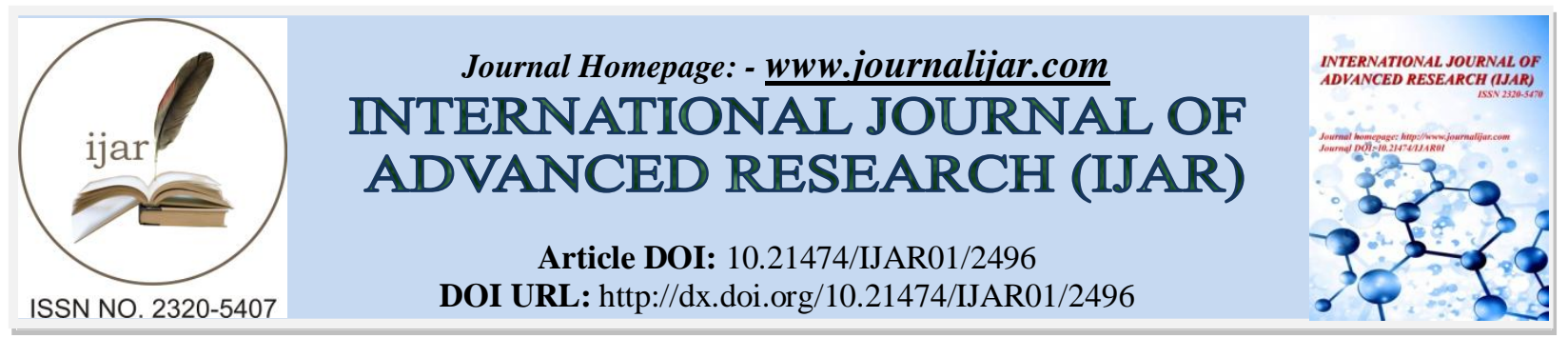

RESEARCH ARTICLE

\title{
DETERMINATION OF PARACETAMOL AND KINETIC PARAMETERS USING NICKEL HEXACYANOFERRATE MODIFIED CARBON PASTE ELECTRODE.
}

Tamiru Gashaw Gete* and Marye Mulugeta Kassaw.

College of Natural and Computational Sciences, Department of Chemistry, Wolaita Sodo University, Ethiopia

\section{Manuscript Info}

Manuscript History

Received: 25 October 2016

Final Accepted: 23 November 2016

Published: December 2016

Key words:-

Paracetamol, Transfer coefficient, heterogeneous electron transfer rate constant,Nickel Hexacyanoferrate, cyclic voltammetry, Modified Carbon Paste Electrode

\section{Abstract}

Electrochemical response characteristics of modified carbon paste electrode towards detection and determination of paracetamol was investigated by cyclic voltammetric technique in $0.1 \mathrm{M}$ acetate buffer solution containing $0.1 \mathrm{M} \mathrm{KCl}$ as supporting electrolyte. Nickel Hexacyanoferrate modified carbon paste electrode was developed by immobilizing different ratios of Nickel Hexacyanoferrate. The best ratio for kinetic parameter and paracetamol determination was $20 \%$ (w/w) NiHCF; 55\% graphite and 25\% (w/w) paraffin oil respectively. For the determination of paracetamol concentration, an accurate amount of $500 \mathrm{mg}$ Paramol,Cadimol,Paracetamol and Panamol tablets were transferred to four different $100 \mathrm{ml}$ volumetric flask and this volume completed with acetate buffer $(\mathrm{pH}$ 7.5). The percentage content or concentration of acetaminophen in these $500 \mathrm{mg}$ paracetamol tablet samples were determined. The detection limit of the modified carbon paste electrode was $8.89 \times 10^{-5} \mathrm{M}$ for paracetamol. The relative standard deviations for the determination of paracetamol was less than 2.\%.Transfer coefficient $(\alpha)$ and heterogeneous electron transfer rate constant $k$ for catalytic reaction were found tobe 0.705 and $2.37 \times 10^{-2} \mathrm{~s}^{-1}$ respectively.

Copy Right, IJAR, 2016,. All rights reserved.

\section{Introduction:-}

The voltammetric study of pharmaceutical drugs is by far the most common application of electrochemistry in pharmaceutical analysis. As a rule many of the pharmaceutically active constituents are readily oxidized or reduced. The functional groups show excellent voltammetric properties in the redox behavior at the working electrode. Electro analytical chemistry along with the use of oxidation-reduction reactions and other charge-transfer phenomena had its origins eight decades ago. Electroanalytical techniques have been shown to be excellent for the determination of pharmaceutical compounds in different matrices. Many of the active constituents of formulations, in contrast to excipients, can be readily oxidized. The selectivity of this method is normally excellent because the analyte can be readily identified by its voltammetric peak potential. The advance in experimental electrochemical techniques in the field of analysis of drugs is because of their simplicity, low cost and relatively short analysis time as compared to other techniques [1].

In voltammetrya time-dependent potential is applied to an electrochemical cell, and the current flowing through the cell is measured as a function of that potential.A plot of current as a function of applied potential is called a 
voltammogram and is the electrochemical equivalent of a spectrum in spectroscopy, providingquantitative and qualitative information about the species involved in theoxidation or reduction reaction [2].

Paracetamol (PAR, N-acetyl-p-aminophenol or acetaminophen) is an effective and safe analgesic agent used to reduce fever, cough and cold. It is also used worldwide for the relief of mild to moderate pain associated with headache, migraine headache and noninflammatory conditions in patients prone to gastric symptoms [3].

Paracetamol described as 4-hydroxyacetanilide or N-acetyl-p-aminophenol and in the US Pharmacopoeia it is known as acetaminophen and its chemical formula, $\mathrm{C}_{8} \mathrm{H}_{9} \mathrm{NO}_{2}$ and its structure is as shown in fig1.

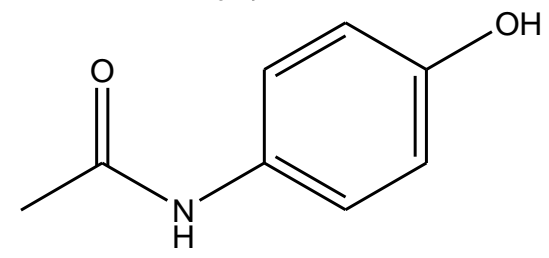

Fig 1:- Structure of paracetamol

Acetaminophen is an odorless, slightly bitter taste white crystalline powder. It is soluble in organic solvents such as methanol and ethanol but slightly soluble in water and ether. Its $\mathrm{pH}$ range is $5.5-6.5$ based on saturated aqueous solution. The melting point of this compound $169-170{ }^{\circ} \mathrm{C}$. Paracetamol is most stable at saturated aqueous solutions. Its $\mathrm{pK}_{\mathrm{a}}$ value is 9.5 in aqueous media. The stability decreases in acid or alkaline conditions. Chemically $\mathrm{N}$-(4-Hydroxyphenyl) acetamide is derived from the interaction of p-aminophenol and an aqueous solution of acetic anhydride [4].

A number of quantitative analytical methods have been reported for paracetamol determination in pharmaceutical formulations, biological samples and even wastewaters, individually or associated to other active compounds (in combination with other drugs). The methods are titrimetric analysis [5], Spectrofluorimetry [6], Chronoamperometry [7], Colorimetry [8], Amperometry [9], Chemiluminescence [10], Spectrophotometry (Uv-spectrophotometry) [11], Derivative Spectrophotometry [12], various kinds of High Performance Liquid Chromatography [13], Quantitative Thin-layer Chromatography (TLC), [14]. Flow Injection Analysis (FIA) (using different methods of detection), [15]. Gas Chromatography [16], Capillary Electrophoresis conducted in single component as well as multi-component systems have to be mentioned [17]. and Electrochemical detection in single component or multi-component systems using different types of working electrodes like glassy carbon electrode, chemically modified glassy carbon electrode, carbon paste electrode, modified carbon paste electrode [18,19-23]. In most of the methods considerable time is required for purification and extraction steps. But the electroanalytical methods do not require purification and extraction process. Due to its electroactive properties, acetaminophen has been also investigated by various electrochemical methods performed in a variety of supporting electrolytes and using different kinds of electrodes [20-22]. In this work, paracetamol concentration and kinetic parameters (Transfer coefficient $(\alpha)$ and heterogeneous electron transfer rate constant, $k$ ) were determined using Nickel Hexacyanoferrate Modified Carbon Paste Electrode in $0.1 \mathrm{M}$ acetate buffer solution containing $0.1 \mathrm{M} \mathrm{KCl}$ as supporting electrolyte.

\section{Experimental part:-}

Reagents and Chemicals:-

Graphite powder (BDH, England), paraffin oil (Nice), pure paracetamol (Addis pharmaceutical factory, Ethiopia), glacial acetic acid (Finken), sodium acetate trihydrate (LobachemiPvt.Ltd., India), and $\mathrm{NaOH}$ (Scharlau, Spain), $\mathrm{HCl}$, Potassium chloride (Nice chemicals Pvt.Ltd.) Nickel chloride (Nice), potassium hexacyanoferrate III (KiraLight, India), paracetamol tablets brand named paramol, paracetamol, panamol and Cadimol were used in the experiment.

\section{Apparatus:-}

All cyclic voltammetric measurements and processing of data were carried out in glass voltammetric cell, using BAS 50W CV voltammetric analyzer, which was connected to Dell Pentium personal computer containing three electrode system, Nickel (II) hexacyanoferrate (III) modified carbon paste electrode (NiHCF) as a working electrode, silver-silver chloride as a reference electrode and platinum wire as auxiliary electrode. The $\mathrm{pH}$ of the buffer solution was measured with a 353 ATC digital $\mathrm{pH}$ meter with combination glass electrode. 1ml Syringe 
(Plastipak, Spain) and Whatman filter paper (Whatman, England) were used for the preparation of the working electrode in the experiment.

\section{Preparation of Nickel (II) Hexacyanoferrate (III):-}

Nickel (II) Hexacyanoferrate (III)compound was prepared by mixing $0.25 \mathrm{~mol} \mathrm{~L}^{-1}$ potassium hexacyanoferrate (III) solution and a $0.5 \mathrm{~mol} \mathrm{~L}^{-1}$ Nickel chloride solution with the atomic ratio of $\mathrm{Ni} / \mathrm{Fe}=2$. The precipitate obtained was filtered in whatman filter paper, washed with distilled water several times and dried at $25^{\circ} \mathrm{C}$ for $72 \mathrm{hrs}$.

\section{Sample preparation of Paracetamol tablet:-}

The content of acetaminophen in four different commercial brands of $500 \mathrm{mg}$ paracetamol tablet was determined. For the analysis of tablet formulation, an accurate amount of each $500 \mathrm{mg}$ paracetamol tablets were transferred to four different $100 \mathrm{ml}$ volumetric flask and this volume completed with acetate buffer $(\mathrm{pH} 7.5) .5 \mathrm{ml}$ of these samples were poured in to the electro chemical cell containing $20 \mathrm{ml}$ of $0.1 \mathrm{M}$ acetate buffer solution containing $0.1 \mathrm{M}$ potassium chloride solution. The final solution was homogenized with a stirrer with the rest solution; the cyclic voltammograms were recorded by cycling the potential between -300 and $+1200 \mathrm{mV} \mathrm{Vs} \mathrm{Ag} / \mathrm{AgCl}$ at a scan rate of $100 \mathrm{mV} / \mathrm{s}$. The percentage content or concentration of acetaminophen in these $500 \mathrm{mg}$ paracetamol tablet samples was determined from the calibration curve.

\section{Result and Discussion:-}

\section{Determination of Paracetamol Using NiHCF Modified Carbon Paste Electrode:-}

The applicability of NiHCF modified carbon paste electrode for the determination of acetaminophen was verified analyzing four different paracetamol tablet samples. The pharmaceutical samples analyzed were collected from medical shops at Mekelle, Ethiopia. Four tablets having acetaminophen were examined for estimation of content of acetaminophen in different brand name paracetamol tablets. Samples of these drugs were produced in Ethiopia and abroad.

The content of acetaminophen was determined using calibration curve method with correlation coefficient $\mathrm{r}^{2}, 0.983$. A concentration range of $25 \mathrm{mM}$ to $35 \mathrm{mM}$ of paracetamol was chosen for calibration curve preparation. Cyclic voltammograms of the tablets at $\mathrm{pH} 7.5$ were recorded under optimized conditions. Analysis of paracetamol tablets available at drug store under different trade names (panamol, paracetamol, paramol and Cadimol) using the proposed cyclic voltammetry determination procedure resulted in the values shown in table 1 .

Table.1:- Amount of paracetamol with the corresponding \% RSD, present in four different brands of paracetamol tablets available in Mekelle drug stores.

\begin{tabular}{|l|l|l|l|l|}
\hline Brand name & $\begin{array}{l}\text { Labeled acetaminophen } \\
\text { content in mg }\end{array}$ & $\begin{array}{l}\text { Acetaminophen found by } \\
\text { calibration curve ,mg }\end{array}$ & $\begin{array}{l}\text { content } \\
\text { Acetaminophen }\end{array}$ & RSD \\
\hline Paramol & 500 & 498 & 99.6 & 2.33 \\
\hline Cadimol & 500 & 492.4 & 98.4 & 2.33 \\
\hline Panamol & 500 & 489.7 & 97.9 & 2.01 \\
\hline Paracetamol & 500 & 496.1 & 99 & 2.05 \\
\hline
\end{tabular}

The content of the tablets in commercial formulations determined by the proposed method was in good agreement with the reported values of the company.

\section{Effect of Paracetamol Concentration on Peak Current:-}

The effect of concentration of paracetamol was studied at NiHCF modified carbon paste electrode in $0.1 \mathrm{M}$ acetate buffer solution containing $0.1 \mathrm{M}$ potassium chloride of $\mathrm{pH} 7.5$ with scan rate $100 \mathrm{mV} / \mathrm{s}$, Fig. 2 below shows the successive enhancement of cyclic voltammograms peak current on increasing paracetamol concentration from $5 \times 10^{-}$ ${ }^{4} \mathrm{M}$ to $7.5 \times 10^{-3} \mathrm{M}$. 


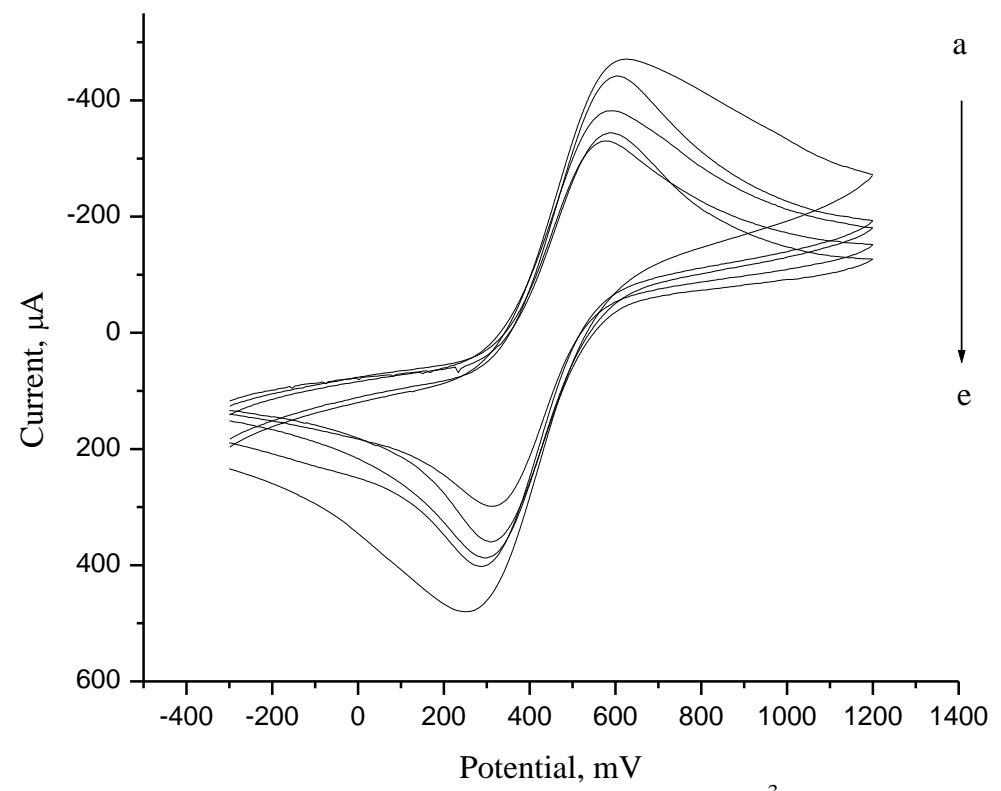

Fig 2:- Cyclic voltammograms of different concentration of paracetamol $\left(10^{-3}\right)(a-e ; a=0.5, b=1, c=2.5, d=5$ and e $=7.5$ ) at NiHCF modified carbon paste electrode in $0.1 \mathrm{M}$ acetate buffer solution containing $0.1 \mathrm{M}$ potassium chloride of $\mathrm{pH} 7.5$ with scan rate $100 \mathrm{mV} / \mathrm{s}$.

The plot of peak current versus the respective concentration of paracetamol was found to be linear in the range of $5 \times 10^{-4} \mathrm{M}$ to $7.5 \times 10^{-3} \mathrm{M}$ with a correlation coefficient $\mathrm{r}^{2}=0.990$ as shown in Fig. 3 below. The enhancement of cyclic voltammograms peak current on increasing paracetamol concentration is due to the presence of more ions in the solution which makes the flow of electrons easy and the molecules collide together. The detection limit of paracetamol was calculated by using the formula (1) and it was found to be $8.89 \times 10^{-5} \mathrm{M}$.

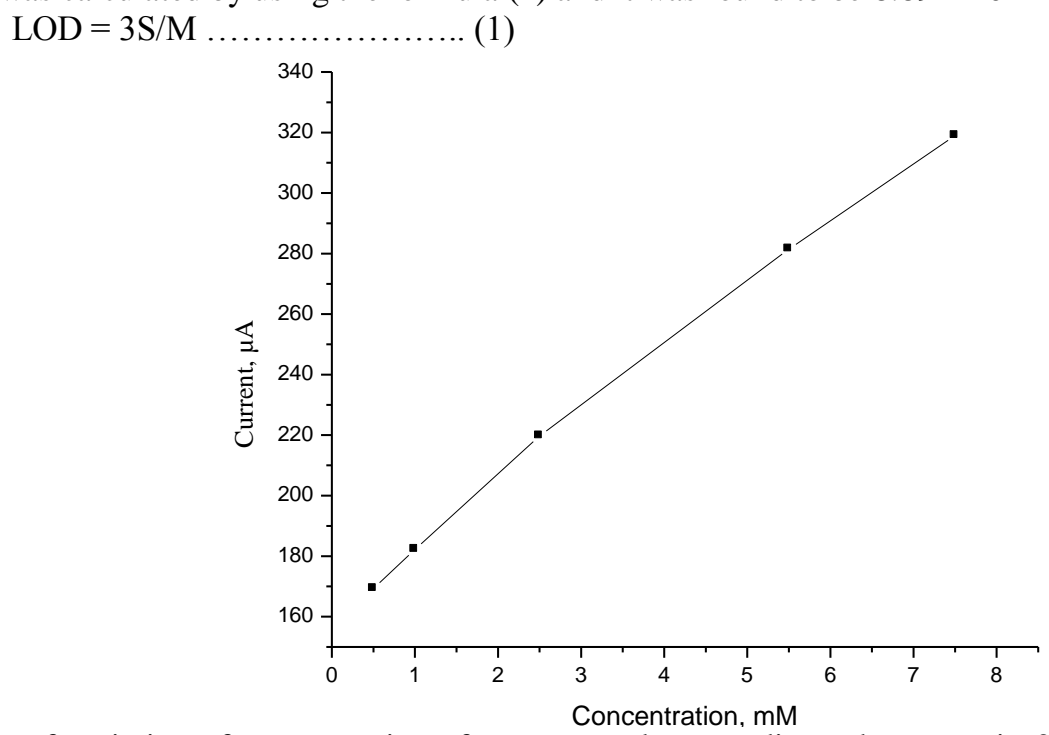

Fig 3:- Effect of variation of concentration of paracetamol on anodic peak current in $0.1 \mathrm{M}$ acetate buffer solution containing $0.1 \mathrm{M}$ potassium chloride of $\mathrm{pH} 7.5$ with scan rate $100 \mathrm{mV} / \mathrm{s}$ at NiHCF modified carbon paste electrode. Determination of kinetic parameters:-

The transfer coefficient $(\alpha)$ can be calculated from the slope of the resulted curve of Ep vs. log v using equation (2) [24].

$E_{P a}=K+\frac{2.3 \mathrm{RT}}{2(1-\alpha) n_{\alpha}} \log v$

Slope $=\frac{2.3 \mathrm{RT}}{2(1-\alpha) n_{\alpha}}$ 
Where $\alpha$ is transfer coefficient, $n_{\alpha}$ is the number of electrons involved in the rate-determining step, $v$ is scan rate, $\mathrm{R}$ is gas constant, $\mathrm{E}_{\mathrm{pa}}$ is peak potential.

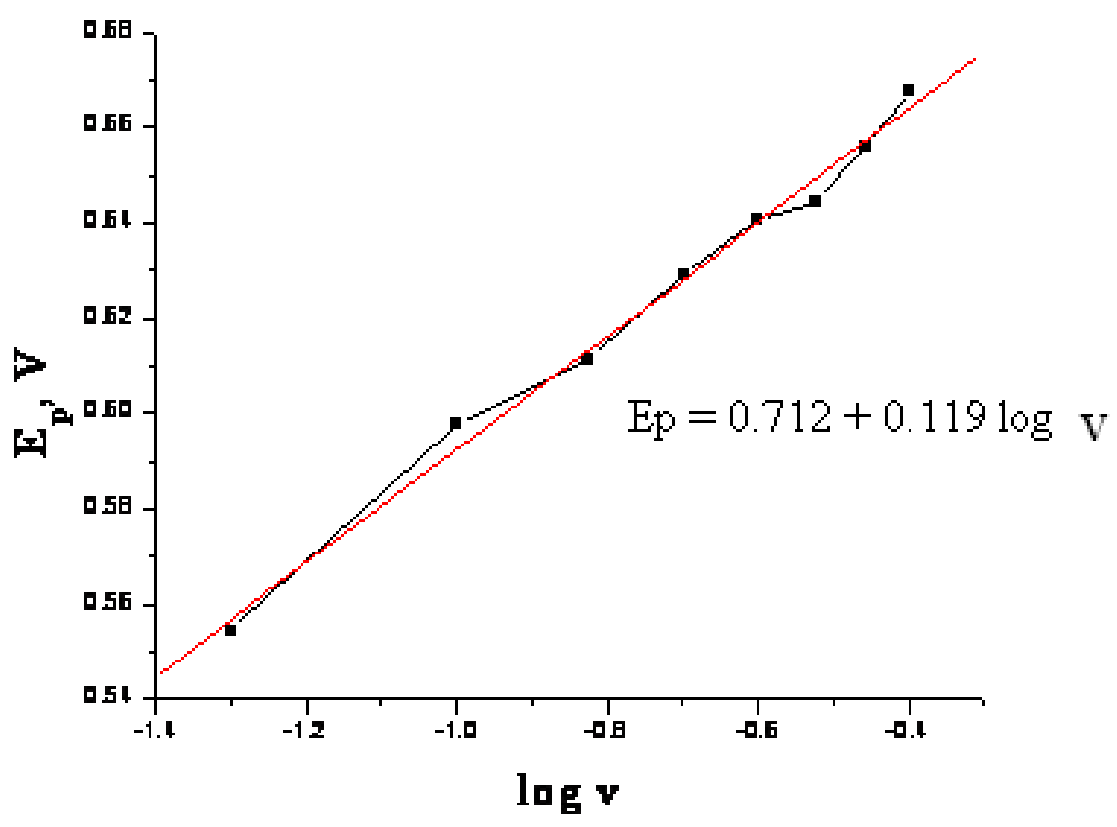

Fig 4:- Graph of $E_{p} v_{s} \cdot \log v$

Based on Fig.4 and Eq. (2), the value of transfer coefficient $(\alpha)$ was calculated as

$$
0.119=\frac{2.3 \mathrm{RT}}{2(1-\alpha) n_{\alpha}}
$$

The value of transfer coefficient $(\alpha)$ from this calculation is 0.705 . Higher value of transfer coefficient $(\alpha)$ indicates deviation from reversible system. By calculating $\alpha$ from the slope of Ep vs. $\log \mathrm{v}$ curve, $k$ can be obtained from equation (3) [24].

$$
\log \mathrm{k}_{\mathrm{s}}=\alpha \log (1-\alpha)+(1-\alpha) \log \alpha-\log \left(\frac{\mathrm{RT}}{\mathrm{nFv}}\right)-\alpha(1-\alpha) \mathrm{nF} \frac{\Delta \mathrm{E}_{\mathrm{p}}}{2.3 \mathrm{RT}} .
$$

Where $\alpha$ is transfer coefficient, $n_{\alpha}$ is the number of electrons involved in the rate-determining step, $k_{s}$ is heterogeneous electron transfer rate constant. Based on Fig.4 and Eq. (2), the value of $\alpha$ was calculated as 0.705 and $n=2$. By substituting the above values in Eq. (3), we found that the heterogeneous electron transfer rate constant $\mathrm{k}=$ $2.37 \times 10^{-2} \mathrm{~s}^{-1}$. The calculated $\mathrm{k}_{\mathrm{s}}$ value and transfer coefficient, $\alpha$ are summarized in Table 2 .

Table 2:- The electrochemical reaction parameters of paracetamol at NiHCF Modified carbon paste electrode.

\begin{tabular}{|l|l|}
\hline \multicolumn{1}{|c|}{ Parameter } & Value \\
\hline Transfer coefficient, $\alpha$ & 0.705 \\
\hline Heterogeneous electron transfer rate constant, $k\left(\mathrm{~s}^{-1}\right)$ & $2.37 \times 10^{-2}$ \\
\hline
\end{tabular}

\section{Conclusion:-}

In this work, NickelHexacyanoferrate Modified Carbon Paste Electrode showed good electrocatalytic response for the determination of paracetamol concentration and kinetic parameters. NickelHexacyanoferrate Modified Carbon Paste Electrode was successfully used for the determination of acetaminophen in paracetamol tablets directly without separation steps with good percentage and precision content of acetaminophen $>97 \%$ and percentage Relative Standard Deviation $<2.5 \%$. Transfer coefficient $(\alpha)$ and heterogeneous electron transfer rate constant $k$ for 
catalytic reaction were found tobe 0.705 and $2.37 \times 10^{-2} \mathrm{~s}^{-1}$ respectively. High sensitivity, low cost, easy preparation, surface regeneration of the NickelHexacyanoferrate Modified Carbon Paste Electrode and the reproducibility of the voltammetric response make the prepared modified system very useful in the construction of simple devices for the determination of acetaminophen in pharmaceutical samples.

\section{Acknowledgements:-}

The authors gratefully acknowledgeP.A.Subramanian $(\mathrm{PhD})$ for his unreserved valuable guidance, consistence encouragement and constructive comment throughout my project work, Mekelle University Department of chemistry, Ethiopian Ministry of Education (MOE) and Addis Pharmaceutical Manufacturing Share Company, for sample and financial support.

\section{References:-}

1. Vinod, K.G.; Rajeev, J.; Keisham, R. N.J.; Shilpi,A. Voltammetric Techniques for the Assay of Pharmaceuticals-a Review. Anal. Biochem.2010, 1-68.

2. David, H. Modern Analytical Chemistry, Depauw University: McGraw-Hill Higher Education, 2000; 461-541.

3. R. N. Goyal, V. K. Gupta, M. Oyama, N. Bachheti, Electrochem. Commun. 2005, 7, 803.

4. Fairbrother, J.E. Acetaminophen. From 'Analytical Profiles of Drug Substances', New York and London,1974; 3,1-109

5. Srivastava, M.K.; Ahmad, S.; Singh, D.; Shukla, I.C. Titrimetric determination of dipyrone and paracetamol with potassium hexacyanoferrate (III) in an acidic medium. Analyst.1985, 110, 735-737

6. JoseLuis, V.; Rosario, B.; Ramiro, A.; Alberto, N. Spectrofluorimetric determination of paracetamol in pharmaceuticals and biological fluids. J.pharm.Biomed.Anal.1995, 13, 1119-1125.

7. Fatibello, F. O;Lupetti K.O.; Vieira, I.C. Chronoamperometric determination of paracetamol using an avocado tissue (Persea Americana). biosensor.talanta. 2001,55(4), 685-692

8. Feng, Y. D.; Wang, Y.; Xu, Y. Determination of acetaminophen by coulometric titration. Analytical Abstracts Database.1997, 25(8), 989

9. Peter, A.V.; Lesley, D.L.S.; Jerome F. M. Amperometric biosensor for the rapid determination of acetaminophen in whole blood. AnalyticaChimicaActa. 1991,248 (2), 361-365.

10. Shulin, Z.; Wenling, B.; Hongyan, Y.; Dan, X.Detection of paracetamol by capillary electrophoresis with chemiluminescence detection. AnalyticaChimicaActa.2006,559(2), 195-199

11. Ghulam, M.; Shujaat, A., Arham, S.; Arshad, M; Muhammad, H.B.; Kalsoom, F, Nadia, S.M.; Izhar,H.Development of a UV-Spectrophotometric method for the simultaneous determination of aspirin and paracetamol in tablets.Sci. Res. Essays.2011, 6(2), 417-421.

12. Ravi kumar, P.; Muralikrishna, M.; Bhanu P.P; b. Anilkumar, B.;Madhusudhan,P.Derivative Spectrophotometric Estimation of Ondansetron and Paracetamol. J Chem.2006, 3 (12), 134-136.

13. Uttam, D.P; Abhijit, V.N; Aruna, V.; Tirumal, A.D; Kiran, V.M. Simultaneous Determination of Aceclofenac, Paracetamol and Chlorzoxazone by HPLC in Tablet Dose Form. J Chem.2009, 6(1), 289- 294.

14. Atul, A.S.; Afsar, M. S; Sanjay, J. S. Simultaneous Determination of Piroxicam and paracetamol Tablets by Thin Layer Chromatography Combined with Densitometry. J Euras Anal Chem.2008, 3(2).

15. Fatibello, F.O.; Vieira, H. J. Spectrophotometric flow injection procedure to indirect determination of paracetamol in pharmaceutical formulations using o-tolidine as reagent.Ecl.QuímSão Paulo.2008, 33(2): 47-54.

16. Belal, T.;Awad, T; Clark, C.R. Determination of paracetamol and tramadol hydrochloride in pharmaceutical mixture using HPLC and GC-MS.J Chromatogr Sci.2009, 47 (10), 849-54.

17. Alison, E.A.; Hilary, J.M.; Ian,D.; Wilson, A.N.; Jeremy, K.N. Application of Capillary Electrophoresis-Mass Spectrometry to the Analysis of Urine Samples From Animals and Man Containing Paracetamol and Phenacetin and Their Metabolites.Anal. Commun. 1997, 34, 41-44.

18. Marcos, F.S.T.; Luiz, H.M; Orlando, F.; Fernando, C.M; Ronaldo, S, N. Determination of Analgesics (Dipyrone and Acetaminophen) in Pharmaceutical Preparations by Cyclic Voltammetry at a Copper (II) Hexacyanoferrate (III) Modified Carbon Paste Electrode.Current Analytical Chemistry. 2009, 5(4), 305.

19. Duncan, T.B; Nipon, T; Sumaporn, K.; Kanita, T. Assay of Acetaminophen in Paracetamol Tablets by Differential Pulse Voltammetry.Kasetsart J. Nat. Sci.2004, 38,510 - 514.

20. Kanita, T.; Nipon, T.; Duncan, T.B. Cyclic voltammetric determination of acetaminophen in paracetamol tablets.J. KMITL Sci. Tech.,2005, 5(3),547

21. Mohammed, Z.; Ttanwee, T.; Halim, A.; Zulkarnain, Z; Gohjoo K.Electrochemical Oxidation of Paracetamol Mediated by MgB2 Micro particles Modified Glassy Carbon Electrode.J. Chem.2011, 8(2), 553-560 
22. Mohammed, Z.; Tanwee, T. ;Abdul,H.A;Zulkarnain,Z.; GohJoo,K. Electrochemical Oxidation of Paracetamol Mediated by Nanoparticles Bismuth Oxide Modified Glassy Carbon Electrode.Int. J. Electrochem. Sci. 2011,6, $279-288$.

23. Sayed, M.G.; Mohsen, B.; Somaye, S.; Mahshid, G.Electrochemical Determination of Acetaminophen in Different Pharmaceutical Forms with Gold Nanoparticles Carbon Paste Electrode.ActaChim. Slov. 2011, 58, 69 -74 .

24. Safavi, A.; Maleki, N.; Moradlou, O. A Selective and Sensitive Method for Simultaneous Determination of Traces of Paracetamol and p-Aminophenol in Pharmaceuticals Using Carbon Ionic Liquid Electrode. Electroanalysis. 2008, 20(19), $2158-2162$

25. O. F. Filho, K. O. Lupetti, I. C. Vieira, Talanta2001, 55, 685.

26. R. N. Goyal, V. K. Gupta, M. Oyama, N. Bachheti, Electrochem. Commun. 2005, 7, 803. 